
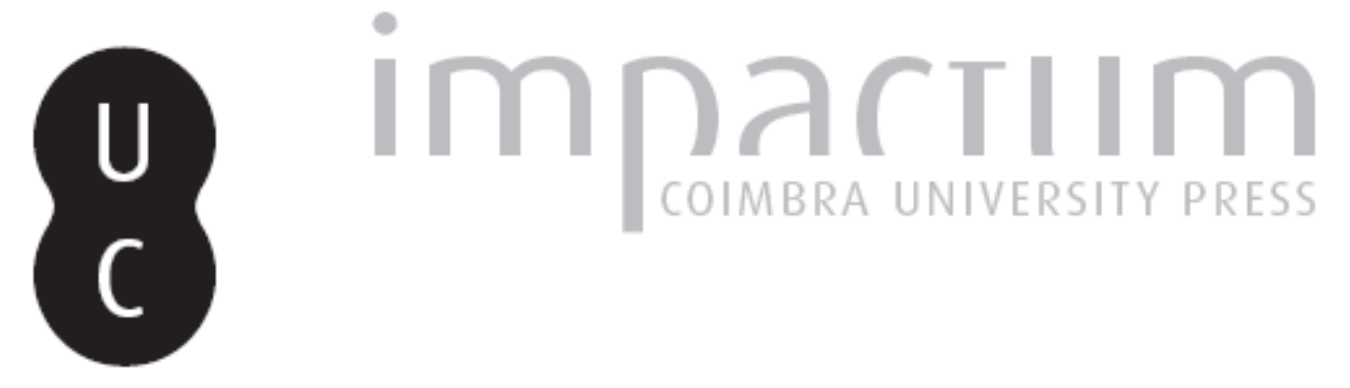

\title{
Perceções dos consumidores domésticos acerca das faturas de água
}

Autor(es): $\quad$ Sá, Patrícia Moura e; Martins, Rita

Publicado por: Imprensa da Universidade de Coimbra

URL persistente:

URI:http://hdl.handle.net/10316.2/38327

DOI:

DOI:http://dx.doi.org/10.14195/2183-203X_42_2

Accessed : $\quad$ 26-Apr-2023 03:33:29

A navegação consulta e descarregamento dos títulos inseridos nas Bibliotecas Digitais UC Digitalis, UC Pombalina e UC Impactum, pressupõem a aceitação plena e sem reservas dos Termos e Condições de Uso destas Bibliotecas Digitais, disponíveis em https://digitalis.uc.pt/pt-pt/termos.

Conforme exposto nos referidos Termos e Condições de Uso, o descarregamento de títulos de acesso restrito requer uma licença válida de autorização devendo o utilizador aceder ao(s) documento(s) a partir de um endereço de IP da instituição detentora da supramencionada licença.

Ao utilizador é apenas permitido o descarregamento para uso pessoal, pelo que o emprego do(s) título(s) descarregado(s) para outro fim, designadamente comercial, carece de autorização do respetivo autor ou editor da obra.

Na medida em que todas as obras da UC Digitalis se encontram protegidas pelo Código do Direito de Autor e Direitos Conexos e demais legislação aplicável, toda a cópia, parcial ou total, deste documento, nos casos em que é legalmente admitida, deverá conter ou fazer-se acompanhar por este aviso.

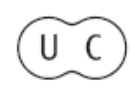




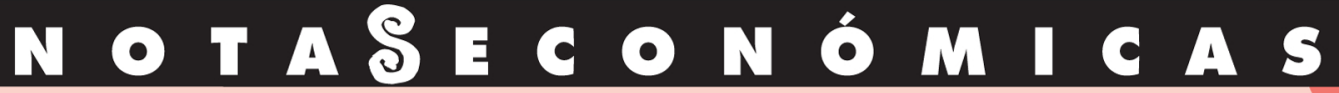

JOÃO SOUSA ANDRADE / ANTÓNIO PORTUGAL DUARTE

PATRÍCIA MOURA E SÁ / RITA MARTINS
OPTIMUM CURRENCY AREAS, REAL AND NOMINAL CONVERGENCE IN THE EUROPEAN UNION

PERCEÇÕES DOS CONSUMIDORES DOMÉSTICOS ACERCA DAS FACTURAS DE ÁGUA 


\section{Perceções dos Consumidores Domésticos acerca das Faturas de Água Residential users' perceptions on water bills}

Patricia Moura e Sá / Rita Martins

FEUC-CICP/UM / FEUC-GEMF

resumo

abstract

Face à importância das faturas na comunicação de informação sobre preços e quantidades consumidas, como reconhecido pelos reguladores, seria desejável que os consumidores compreendessem os sinais preço e outra informação relevante aí transmitidos. Para tal, as faturas devem comunicar de forma clara como são determinados os valores a pagar, as consequências financeiras de consumir mais ou menos, a adequação dos padrões de consumo e a relevância de consumos parcimoniosos.

Assente na realização de focus groups, este artigo investiga as principais razões que explicam o elevado desconhecimento dos consumidores domésticos relativamente às suas contas de água e faz um conjunto de recomendações para a melhoria do documento fatura. De entre estas, a eliminação de tecnicismos, a valorização da inclusão de um referencial de consumo e uma melhor explicitação da relação entre consumo e encargos suportados merecem destaque. Estes elementos afiguram-se essenciais para ultrapassar os problemas de desconfiança e desinteresse identificados e dotar as políticas preço e não preço de eficácia na moderação dos consumos.

Palavras-chave: Água, faturas, gestão da procura, perceções, consumidores domésticos.
Given the importance of invoices in communicating information on prices and quantities consumed, as acknowledged by regulators, it would be of great importance that consumers could look at invoices and understand price signals and other relevant information. Invoices should clearly give the explanation of the amount to be paid and communicate the financial consequences of consuming more or less, the adequacy of consumption patterns and the relevance of parsimonious water consumption.

Based on data collected by means of focus group interviews, the current paper investigates reasons that might be behind the low level of knowledge of domestic consumers regarding their water invoices and makes some recommendations to improve this billing document. Among such improvement opportunities are: removing some unnecessary technical jargon, including a benchmark to assess the level of individual consumption and better clarifying the link between consumption level and amount paid. Adopting such suggestions seems to be essential to overcome part of the distrust and apathy problems identified and to foster the effectiveness of price and non-price policies in promoting parsimonious consumption behaviours.

Keywords: Water, Invoices, Demand Management, Perceptions, Domestic Consumers

JEL Classification: D12; L95; Q25 
A comunicação de informação sobre serviços essenciais é crucial para que os consumidores possam fazer escolhas racionais. De entre essas informações, preços e quantidades são elementos fundamentais. Neste sentido, o papel das faturas é incontornável na medida em que são um veículo que chega a todos os clientes numa base regular.

Relatórios recentes, publicados por organismos internacionais como a ONU (Albuquerque, 2014) e a OCDE (OCDE, 2013), identificam os baixos níveis de literacia e de numeracia como obstáculos ao exercício do direito à informação e chamam a atenção para a necessidade de a informação ser transmitida de forma correta mas simples, para ser compreendida por todos. Efetivamente, a literacia abrange um conjunto de aptidões desde a descodificação de palavras ou frases até à compreensão, interpretação e avaliação de textos complexos, enquanto a numeracia envolve capacidades para lidar com uma situação ou resolver um problema concreto, analisando conteúdo matemático, informação ou ideias representadas de múltiplas formas (OECD, 2013:59). Ambas, e em especial a numeracia dada a natureza da informação constante das faturas, podem afetar a compreensão do documento e suscitar atitudes indesejáveis, como a desconfiança.

Em Portugal, no que se refere aos serviços de águas, o direito à informação está consagrado no Decreto-Lei n. ${ }^{\circ}$ 194/2009, de 20 de agosto, que estabelece o regime jurídico dos serviços municipais de abastecimento público de água, de saneamento de águas residuais urbanas e de gestão de resíduos urbanos. Conforme disposto no n. ${ }^{\circ} 1$ do artigo $61 .^{\circ}$, "os utilizadores têm o direito a ser informados de forma clara e conveniente pela entidade gestora das condições em que o serviço é prestado, em especial no que respeita aos tarifários aplicáveis". Já antes da publicação deste decreto-lei, o "Dever de informação" tinha sido explicitamente reconhecido na Lei dos Serviços Públicos Essenciais (Lei $n .{ }^{\circ} 23 / 1996$ de 26 de julho), especificamente no $n .{ }^{\circ} 1$ do artigo $4 .^{\circ}$, o qual dispõe que "o prestador do serviço deve informar convenientemente a outra parte das condições em que o serviço é fornecido e prestar-lhe todos os esclarecimentos que se justifiquem, de acordo com as circunstâncias."

Trabalhos anteriores sobre o caso português revelam que os consumidores desconhecem elementos críticos das suas faturas de água (Martins e Sá, 2011; Monteiro et al., 2014). O tarifário e a faturação e leitura são, de acordo com o regulador setorial correspondente - a Entidade Reguladora dos Serviços de Águas e Resíduos (ERSAR) - os motivos que têm originado mais reclamações sem fundamento. Neste sentido, é razoável admitir que o desconhecimento referido se deva, entre outros fatores, a características do documento fatura. Esta mesma ideia é assumida pela ERSAR, que tem vindo ao longo dos últimos anos a emitir um conjunto de recomendações a este respeito (veja-se em especial a Recomendação Sobre o Conteúdo das Faturas (ERSAR 1/2010)), as quais culminaram em 2015 no impulso dado à aplicação da Lei da Fatura Detalhada (Lei n. ${ }^{\circ}$ 12/2014, de 6 de março), para a qual a ERSAR disponibiliza um conjunto de notas explicativas e um modelo de fatura a aplicar por todos os operadores. A Lei n. ${ }^{\circ}$ 12/2014 surge no contexto do Plano de Reestruturação do Setor das Águas que procede à agregação de sistemas multimunicipais que operam em alta. Apresentado publicamente pelo Governo com argumentos de promoção de eficiência e equidade territorial, para os consumidores domésticos este Plano tem como consequência imediata a inclusão de informação sobre as componentes de custo do serviço prestado pelos operadores em alta aos sistemas municipais. Por imposição legislativa, a fatura passará assim a incluir "informação relativa ao custo médio unitário dos serviços prestados pelas entidades gestoras [...] em alta", nos termos do ${ }^{\circ}{ }^{\circ} 2$ do artigo $4 .^{\circ}$ do Decreto-Lei n. ${ }^{\circ} 114 / 2014$.

Internacionalmente, diversas entidades, em países como os EUA, a Austrália, o Canadá ou o Reino Unido, realizam ações de apoio à interpretação das faturas e têm criado sítios na internet que visam ajudar na divulgação/compreensão de informação relevante. 
No que concerne à literatura sobre o tema, a ênfase tem sido colocada na estimação de funções procura e no cálculo das correspondentes elasticidades. Em termos científicos, é portanto escassa a literatura dedicada ao papel das faturas, sendo Binet et al. (2013) e Gaudin (2006) duas exceções conhecidas. Em especial a literatura sobre a transmissão de informação "preço" e "não-preço" aplicada aos serviços de águas é muito parca. Mesmo tratando-se da estimação da procura, pouco são os estudos científicos que se debruçam sobre a perspetiva comportamental da mesma (Correia e Roseta-Palma, 2014). Para além do papel dos preços, também é usual as estimações da procura residencial investigarem a influência estatística de variáveis socioeconómicas, principalmente procurando estimar a elasticidade rendimento da procura mas utilizando também a idade, os níveis educacionais, a dimensão do agregado familiar e dados de natureza climatérica, como variáveis explicativas. Poucos estudos dedicam atenção a fatores psicológicos, como atitudes, conhecimento, perceções e valores na estimação da procura (Van den Bergh, 2008).

Tendo em conta este quadro, o presente artigo pretende identificar as principais razões que podem estar a contribuir para o desconhecimento dos consumidores domésticos portugueses relativamente às faturas e analisar as suas consequências. $\mathrm{O}$ conhecimento mais aprofundado de tais razões afigura-se crucial para melhorar a qualidade da comunicação via fatura, estabelecendo recomendações mais eficazes quanto ao seu conteúdo e forma. O presente estudo é porventura o primeiro a olhar para a comunicação via fatura a partir da perspetiva dos clientes, recolhida a partir da realização de focus groups, os quais permitem fazer emergir dimensões de um problema em análise, tirando partido da interação entre os participantes. Fundamentar as recomendações não só na literatura e nas boas práticas internacionais mas também nas opiniões dos clientes é o principal propósito deste trabalho.

A eficácia das políticas públicas que se queiram implementar, e que são particularmente necessárias no setor das águas dada a escassez do recurso e a sua importância vital, exige que elas sejam compreendidas pelos consumidores. Para que estes colaborem, mudando atitudes e comportamentos, é fundamental que entendam as medidas desenhadas com este intuito. Contribuir para a remoção de algumas das barreiras que possam estar a prejudicar o envolvimento dos consumidores com a prossecução dos objetivos de sustentabilidade do recurso, em particular aquelas que se relacionem com deficiências na comunicação via fatura, é outra das finalidades da presente investigação.

$\mathrm{O}$ artigo está estruturado em seis secções. $\mathrm{Na}$ introdução, estão enunciados os principais fundamentos do trabalho, bem como identificados os objetivos da pesquisa. Em seguida, na secção 2, são enquadradas as principais politicas públicas desenhadas com o intuito de promover a racional utilização da água, com destaque para as políticas que atuam do lado da procura e reforçando a importância da comunicação de preços e quantidades. A secção 3 apresenta sumariamente o contexto em estudo - os serviços de águas em Portugal - e descreve as técnicas de recolha e análise de dados aplicadas no estudo. A apresentação e discussão dos resultados é feita na secção 4, onde são identificadas e estruturadas as principais razões do desconhecimento das faturas e analisadas algumas reações dos clientes ao documento fatura. $\mathrm{Na}$ secção 5, apresentam-se diversas recomendações de política para a melhoria da comunicação através da fatura. Finalmente, na secção 6 , apresentam-se as conclusões.

\section{Políticas públicas para a promoção do uso recional da água}

A escassez do recurso água foi formalmente assumida pelas Nações Unidas em 1992, quando, no âmbito da International Conference on Water and Environment, foi conferido à água o estatuto de bem económico e ambiental. Desde então tornaram-se mais ativas as políticas públicas com vista à promoção de um uso racional e parcimonioso do recurso. Efetivamente, tornou-se consensual que as soluções para o aumento da procura de água, em consequência do crescimento/concentração da população e do aumento da atividade económica, não se devem ficar apenas pela expansão da oferta, devendo contemplar também a gestão da procura. 
Neste sentido, na Europa, a Diretiva 2000/60/CE de 23 de outubro de 2000 do Parlamento Europeu e do Conselho, conhecida como Diretiva Quadro da Água (DQA), reconhece o papel dos preços como instrumento a privilegiar no âmbito das políticas do lado da procura, ao estabelecer, no n. ${ }^{\circ} 1$ do seu artigo $9 .^{\circ}$, que os Estados-Membros têm de assegurar que "as políticas de estabelecimento de preços da água deem incentivos adequados para que os consumidores utilizem eficazmente a água, e assim contribuam para os objetivos ambientais da presente diretiva". Em Portugal, a Lei n. ${ }^{\circ}$ 58/2005 de 29 de dezembro, conhecida como Lei da Água, transpôs a DQA para a ordem jurídica portuguesa e definiu as bases e o quadro institucional para a gestão sustentável dos recursos hídricos, designadamente sublinhando a necessidade da recuperação integral de custos, por via da aplicação dos princípios do utilizador/poluidor pagador.

Estão identificados na literatura dois tipos de políticas para atuar do lado da procura: as políticas "preço" e as "não-preço". De uma forma geral, as medidas preço passam pela definição de sistemas tarifários que penalizem consumos considerados excessivos, com vista a transmitir sinais da importância de adotar consumos parcimoniosos. Assim, na maior parte dos países da OCDE são aplicados esquemas tarifários com preços crescentes por blocos de consumo (OCDE, 2010), reconhecidos na literatura económica como Increasing Block Tariffs (IBT). A literatura sobre a estimação de funções procura revela de forma algo sistemática fracas elasticidades preço da procura $^{1}$, o que tem sido explicado pelo carácter essencial do serviço, sobretudo para determinados níveis de consumo. Nalguns contextos, este tipo de resultado fundamenta a definição do preço do primeiro escalão a níveis abaixo daqueles que assegurariam a recuperação integral de custos, procurando subsidiar os menores consumos através do agravamento do preço para escalóes de consumo mais elevados. Acresce que, de entre os custos associados aos serviços de águas, os custos fixos (normalmente ligados às infraestruturas e redes) representam uma parcela significativa dos custos totais. Isto fundamenta muitas vezes a definição de tarifas fixas que, ao serem cobradas em simultâneo com parcelas variáveis, podem dificultar a interpretação dos sinais preço veiculados via IBT. A tentativa de acomodar um conjunto de objetivos diversos, por vezes mesmo contraditórios entre si, resulta quase sempre em esquemas tarifários complexos (Martins e Sá, 2011 e Martins et al., 2013). Por outro lado, o conhecimento do preço marginal ou a reação aos preços médios são questões que permanecem pouco claras para os investigadores (Nataraj e Hanemann, 2011). Nieswiadomy e Molina (1989) constitui um exemplo raro de um estudo onde os autores trabalham com a perceção do preço.

Em face da fraca elasticidade preço da procura, as políticas preço têm de ser complementadas com medidas "não-preço", como campanhas de sensibilização, muitas vezes associadas à moderação dos consumos, ou, em casos mais extremos, com imposição de restrições à utilização de água. Estas campanhas recorrem a uma multiplicidade de canais, procurando promover a utilização de equipamentos poupadores de água (por exemplo, redutores de caudal nas torneiras, autoclismos de dupla descarga, máquinas de lavar mais eficientes e com cargas cheias) ou alertando para a necessidade de redobrar a atenção sobre os consumos em períodos de pico, que acontecem em geral em momentos de menor disponibilidade do recurso. Nestas campanhas podem estar envolvidos múltiplos atores, desde os operadores dos serviços, aos reguladores, instituições de ensino, até aos consumidores finais. A investigação sobre a eficácia destas medidas sobre 0 consumo é escassa, constituindo Ferraro e Price (2013) uma exceção conhecida.

Por outro lado, em especial nos países desenvolvidos, assiste-se também a campanhas direcionadas para o incentivo à ingestão de água da torneira em substituição de água engarrafada, promovendo a ideia de que a água da torneira é segura para consumo humano.

A eficácia de qualquer das estratégias depende, em grande parte, do modo como são comunicadas àqueles a quem se dirigem. Quem produz a informação deverá preocupar-se com a utilização de linguagem adequada, que seja rigorosa mas ao mesmo tempo compreensível para a generalidade dos consumidores dos serviços, enfatizando o que é mais relevante e não

1 Worthington e Hoffman (2008) ou Arbués et al. (2003) constituem importantes referências no âmbito da revisão de literatura sobre modelos de estimação de funções procura de água. 
descurando a importância de captar o interesse do destinatário. Por sua vez, quem recebe a informação deve estar preparado para despender algum esforço para absorver a informação transmitida e assumir a sua quota de responsabilidade. Uma deficiente comunicação potencia a desconfiança e pode conduzir à desresponsabilização e ao desinteresse.

\section{Abordagem metodológica}

Na presente secção apresenta-se o desenho da pesquisa, referindo as principais técnicas de recolha e análise dos dados. Entendeu-se, ao mesmo tempo, que seria essencial explicar brevemente o contexto em que o estudo se realizou. Assim, descreve-se sumariamente o setor das águas em Portugal, dando natural destaque ao modo como as faturas transmitem informação sobre as quantidades consumidas e como essas se repercutem nos valores a pagar, em particular na determinação dos montantes relativos ao pagamento dos três tipos de serviços cobrados em conjunto: abastecimento de água (AA), saneamento de águas residuais (SAR) e resíduos sólidos urbanos (RSU).

\subsection{Os serviços de águas em Portugal}

Por razões relacionadas com os investimentos avultados e as exigentes obrigações de serviço de interesse geral, o setor das águas em Portugal (AA e SAR) tem características de monopólio natural, reunindo condições para a existência de um único prestador ao nível local ou regional de modo a minimizar os custos envolvidos. Assim, e no que concerne ao fornecimento em baixa (distribuição aos consumidores finais no caso do AA e drenagem no SAR) a provisão de serviços é feita por monopólios locais. O setor é consideravelmente fragmentado existindo, em regra, um único prestador (entidade gestora - EG) em cada município, com alguma diversidade em termos de modelos de gestão, como pode ser observado na tabela 1.

Tabela 1 - Entidades gestoras e modelos de gestão no AA e no SAR em baixa

\begin{tabular}{|c|c|c|c|c|c|c|}
\hline & \multicolumn{3}{|c|}{ AA } & \multicolumn{3}{|c|}{ SAR } \\
\hline Modelos de gestão & $\begin{array}{l}\text { Entidades } \\
\text { gestoras }\end{array}$ & $\begin{array}{l}\text { Concelhos } \\
\text { abrangidos }\end{array}$ & $\begin{array}{l}\text { Densidade } \\
\text { populacional }\end{array}$ & $\begin{array}{l}\text { Entidades } \\
\text { gestoras }\end{array}$ & $\begin{array}{r}\text { Concelhos } \\
\text { abrangidos }\end{array}$ & $\begin{array}{l}\text { Densidade } \\
\text { populacional }\end{array}$ \\
\hline $\begin{array}{l}\text { Concessões } \\
\text { multimunicipais }\end{array}$ & 1 & 1 & 142 & - & - & - \\
\hline Concessões municipais & 27 & 32 & 243 & 22 & 22 & 254 \\
\hline Delegações estatais & 2 & 2 & 6319 & -- & -- & - \\
\hline $\begin{array}{l}\text { Parcerias } \\
\text { Estado/municípios }\end{array}$ & 1 & 10 & 225 & 1 & 10 & 226 \\
\hline $\begin{array}{l}\text { Empresas municipais ou } \\
\text { intermunicipais }\end{array}$ & 24 & 29 & 196 & 25 & 30 & 196 \\
\hline $\begin{array}{l}\text { Serviços municipalizados } \\
\text { ou intermunicipalizados }\end{array}$ & 21 & 23 & 284 & 19 & 21 & 327 \\
\hline Serviços municipais & 191 & 191 & 50 & 197 & 197 & 61 \\
\hline Outros submodelos & 99 & 18 & 42 & -- & -- & -- \\
\hline Total & 366 & & & 264 & & \\
\hline
\end{tabular}

Fonte: ERSAR (2014).

O elevado número de operadores no AA em baixa deve-se ao facto de a maioria do serviço ser assegurado por serviços municipais (191) e ao número expressivo (99) de pequenas entidades, sobretudo juntas de freguesia ou associações de consumidores, que abastecem, no seu conjunto, um universo de apenas 68 mil habitantes e que são responsáveis pela maioria dos casos em que há mais do que uma EG a operar no mesmo concelho.

Perante esta multiplicidade de monopólios locais, cabe ao regulador não só evitar o abuso de posição dominante como assegurar alguma harmonização em certas condições de fornecimento 
dos serviços. No que se refere ao objetivo de proteção dos consumidores, compete à ERSAR promover a qualidade dos serviços prestados pelos operadores e garantir preços socialmente aceitáveis, o que se materializa no cumprimento dos seguintes princípios: essencialidade, indispensabilidade, universalidade, equidade, fiabilidade e eficiência de custos associada à qualidade dos serviços (ERSAR, 2013). De entre os esforços de harmonização, merecem referência as iniciativas conducentes à redução da heterogeneidade nos esquemas tarifários praticados (em especial no que respeita ao número e dimensão de escalões e tipos de taxas cobradas) e as recomendações referentes às faturas.

De facto, a partir de 2009, as intervenções da ERSAR com o intuito de garantir o direito dos consumidores a informação correta, fiável e clara foram sendo reforçadas. Essas intervenções consubstanciam-se fundamentalmente em três recomendações: a Recomendação 1/2009 "Recomendação Tarifária", a Recomendação 2/2010 - "Critérios de Cálculo" e a Recomendação 1/2010 - "Conteúdos das Faturas".

De acordo com as recomendações da ERSAR, as estruturas tarifárias relativas ao serviço de AA devem sempre incluir duas componentes: uma componente fixa e uma componente variável (volumétrica) com quatro escalões de preços crescentes (IBT). Está também estabelecido que deverão existir tarifários diferenciados para diferentes tipologias de consumidores (residenciais e não residenciais), bem como tarifários especiais para famílias de baixo rendimento e para famílias numerosas.

Para efeitos de faturação, o consumo pode ser real ou estimado, havendo lugar a acertos pontuais no segundo caso. Juntamente com o AA são cobrados mensalmente serviços de SAR e de RSU. Relativamente ao SAR e aos RSU, em regra são cobrados encargos fixos para cada um dos serviços e, uma vez que não existe uma medição própria, a cobrança da componente variável é indexada ao consumo de água, devendo ser aplicados igualmente quatro escalões.

É expectável que a complexidade dos esquemas tarifários aliada à cobrança de outros serviços em conjunto com o AA esteja a contribuir para algumas das dificuldades sentidas pelos consumidores na compreensão das suas faturas.

\subsection{Técnicas de recolha e análise das perceções dos consumidores a respeito das faturas}

O presente artigo usa uma abordagem qualitativa para identificar as principais razões do desconhecimento das faturas de água, o qual tinha já ficado patente em estudos anteriormente publicados, como referido anteriormente, e analisar algumas consequências, nomeadamente ao nível da eficácia das políticas públicas, do modo como os consumidores encaram o documento fatura de água. Tendo em conta a ausência de referenciais teóricos sobre o assunto, a opção por uma abordagem qualitativa, que permita fazer emergir as dimensões fundamentais do problema, é amplamente justificada.

Sendo necessário ouvir consumidores domésticos e considerando que a informação a recolher poderia claramente beneficiar da interação que entre eles se estabelecesse, considerou-se que fazia todo o sentido usar a técnica de focus group (FG). Como destacado por Bryman e Bell (2007), os FG são particularmente adequados quando se pretende explorar um tema específico em profundidade, devendo o(s) moderador(es) dotar-se de um guião bastante aberto e flexível por forma a permitir a extração das ideias e perspetivas dos participantes. A entrevista em grupo permite "que cada um avalie as razões pelas quais outros detêm uma determinada opinião" (Bryman e Bell, 2007: 512) e assim construir novas perspetivas que resultam do grupo no seu todo.

Neste estudo foram constituídos três grupos, envolvendo 21 indivíduos, e realizadas, portanto, três entrevistas em dias distintos do mês de março de 2014. Embora a técnica não exija que se defina à partida o número de $\mathrm{FG}$ a realizar no âmbito de um dado estudo, admitindo a utilização do princípio da "saturação" (que ocorre quando pela sucessiva repetição de ideias se pode 
razoavelmente antecipar o que resultaria do FG seguinte), entendeu-se adequada a definição de três grupos, na medida em que permitiam refletir perfis sociodemográficos distintos e acomodar com alguma homogeneidade cerca de 20 participantes. A ideia da estratificação dos FG é admitida por Bryman e Bell (2007) e defendida por Morgan (1998) com a alegação de que a homogeneidade aumenta a compatibilidade entre os membros e pode enriquecer a discussão. Neste trabalho essa homogeneização visou explorar melhor algumas dimensões (como o nível de qualificações) que se suspeitava explicarem diferentes níveis de conhecimento e familiaridade com as faturas. A constituição de grupos com características assumidamente distintas entre si (como foi o caso no presente estudo) permite depois fazer uma leitura comparada de alguns resultados.

Já no que se refere ao número de participantes em cada FG, as opiniões prevalecentes são de que discussões de grupo com mais do que oito participantes tornam-se difíceis de gerir (Blackburn e Stokes, 2000; Bryman e Bell, 2007), enquanto grupos com menos de seis elementos devem ser empregues apenas quando o nível de envolvimento com o tópico é muito elevado e o objetivo é obter relatos mais ou menos detalhados de experiências pessoais, o que não se aplica no caso em questão.

Neste estudo foi elaborado um guião de questões, o qual admitia uma elevada flexibilidade na condução das entrevistas realizadas em cada FG, tal como a técnica requer, de forma a se garantir um livre fluir de ideias entre os membros. A sequência de questões teve em conta a necessidade de colocar à vontade os participantes e de os familiarizar com o tópico, dando oportunidade para expressarem opiniões e recordarem experiências pessoais que potencialmente tivessem tido com as faturas de água. O guião, sendo genericamente comum a todos os grupos, foi ligeiramente adaptado para cada um deles. Para fazer emergir um maior número de aspetos e refrescar a memória dos participantes relativamente ao conteúdo e configuração das faturas, num determinado momento das entrevistas, foram apresentadas três faturas a título meramente exemplificativo.

A caracterização sociodemográfica dos grupos é feita na Tabela 2.

Tabela 2 - Descrição dos focus groups

\begin{tabular}{|c|c|c|c|}
\hline & FG1 & FG2 & FG3 \\
\hline Número de participantes & 7 & 7 & 7 \\
\hline $\begin{array}{r}\text { Feminino } \\
\text { Masculino }\end{array}$ & $\begin{array}{l}3 \\
4 \\
\end{array}$ & $\begin{array}{l}3 \\
4 \\
\end{array}$ & $\begin{array}{l}7 \\
0\end{array}$ \\
\hline $\begin{array}{r}18 \text { a } 35 \text { anos } \\
35 \text { a } 50 \text { anos } \\
50 \text { a } 65 \text { anos } \\
>65 \text { anos }\end{array}$ & $\begin{array}{l}0 \\
6 \\
1 \\
0\end{array}$ & $\begin{array}{l}1 \\
1 \\
4 \\
1\end{array}$ & $\begin{array}{l}1 \\
5 \\
1 \\
0\end{array}$ \\
\hline $\begin{array}{rr}\text { Habilitações } & \text { Ensino básico } \\
\text { Ensino secundário } & \\
& \text { Licenciatura ou superior }\end{array}$ & $\begin{array}{l}0 \\
0 \\
7\end{array}$ & $\begin{array}{l}5 \\
2 \\
0\end{array}$ & $\begin{array}{l}0 \\
0 \\
7\end{array}$ \\
\hline $\begin{array}{r}\text { Formação de base } \\
\qquad \begin{array}{r}\text { Economia e/ou gestão } \\
\text { Outras áreas }\end{array} \\
\end{array}$ & $\begin{array}{l}6 \\
1 \\
\end{array}$ & $\begin{array}{l}\text { n.a. } \\
\text { n.a. }\end{array}$ & $\begin{array}{l}0 \\
7\end{array}$ \\
\hline Duração da entrevista (minutos) & 70 & 60 & 80 \\
\hline
\end{tabular}

O primeiro focus group (FG1) foi constituído por pessoas com formação base em economia ou gestão (ao nível da licenciatura ou superior) e que supostamente estariam mais à vontade na compreensão dos esquemas tarifários. Por seu turno, no segundo grupo (FG2) participaram consumidores sem formação académica superior. Finalmente, do terceiro grupo (FG3) fizeram parte indivíduos que nas suas tarefas profissionais são preparadores de informação em diferentes domínios e que, por essa razão, tendem a ter alguma experiência em ajudar outros a 
compreender dados complexos. Em função dessas diferenças, antecipava-se que se estivesse perante diferentes níveis de literacia e numeracia, os quais poderiam ter um impacto significativo no modo como os consumidores encaram a informação constante das faturas. Esperar-se-ia assim que as dificuldades em interpretar alguma da informação veiculada nas faturas fossem maiores entre os participantes no FG2.

Com o acordo dos participantes, as conversas foram registadas em suporte áudio. A duração foi variável, mas situou-se em qualquer dos casos entre os 60 e os 80 minutos.

As transcrições serviram depois de base à análise de conteúdo, a qual permitiu identificar categorias e relacioná-las entre si. De facto, a análise de conteúdo tem como intuito reinterpretar e extrair significados de dados qualitativos, valorizando os contextos em que as afirmações foram proferidas. Esse trabalho consubstanciou-se na análise de resultados que se apresenta em seguida. Dada a riqueza de algumas afirmações transcritas, faz-se assumidamente um uso extensivo de citações dos participantes para suportar as principais constatações.

\section{Apresentação e discussão de resultados}

Como é comum em estudos de natureza qualitativa, não existia à partida uma estrutura pré-definida para descrever os dados, pelo que as categorias de análise e a respetiva arrumação foram surgindo à medida que os dados foram tratados e a sua leitura foi sendo feita. Assim, a apresentação e a discussão dos resultados é feita em duas fases. Na primeira organizam-se as razões apontadas para o desconhecimento das faturas e na segunda são avaliadas as reações negativas dos consumidores perante o documento fatura. No seu conjunto, estas interpretações permitem ter uma noção dos principais aspetos a melhorar para que a comunicação via fatura se torne mais eficaz, conforme se recomenda na secção 5.

\subsection{Razões do desconhecimento relativo às faturas}

As discussões realizadas no âmbito dos FG procuraram fazer emergir um conjunto nuclear de razões que explicassem o desconhecimento dos consumidores domésticos no que respeita à sua conta de serviços de águas.

Da auscultação feita à opinião sobre o documento fatura, identificou-se um conjunto de motivos que parecem estar na base do desconhecimento revelado. Tal como evidenciado na Tabela 3 , de uma forma resumida, essas razões foram arrumadas em quatro dimensões: i) linguagem, ii) complexidade, iii) forma e iv) desinteresse. 


\begin{tabular}{|c|c|}
\hline $\begin{array}{l}\text { - Tecnicismo } \\
\text { - Opacidade }\end{array}$ & Linguagem \\
\hline $\begin{array}{l}\text { - Multiplicidade de itens cobrados } \\
\text { - Diversos serviços (AA+AR+RSU) } \\
\text { - Componentes fixas e variáveis } \\
\text { - Escalões } \\
\text { - Diferentes taxas }\end{array}$ & Complexidade \\
\hline $\begin{array}{l}\text { - Desorganização } \\
\text { - Falta de destaque ao é mais importante } \\
\text { - Letra pequena } \\
\text { - Fracos suportes gráficos } \\
\text { - Pouco atrativo }\end{array}$ & Forma \\
\hline $\begin{array}{l}\text { - Baixo peso nas despesas familiares } \\
\text { - Não haver possibilidade de escolha } \\
\text { (de prestador e de serviços substitutos) } \\
\text { - Elevado peso dos encargos fixos }\end{array}$ & Desinteresse \\
\hline
\end{tabular}

De uma forma geral, as razões enunciadas foram transversais aos três $F G$, embora tenham sido reveladas com diferentes intensidades. A Tabela 4 procura evidenciar as diferenças encontradas entre os três $F G$, e avaliá-las em função da frequência com que foram referidas algumas preocupações e da veemência com que os problemas foram expostos.

Tabela 4 - Intensidade das razões do desconhecimento por focus group

\begin{tabular}{|l|c|c|c|} 
& FG1 & FG2 & FG3 \\
\hline Linguagem & + & +++ & ++ \\
\hline Complexidade & ++ & ++ & + \\
\hline Forma & + & ++ & +++ \\
\hline Desinteresse & ++ & + & Não revelado \\
\hline
\end{tabular}

+: Revelada esporadicamente e/ou de forma ligeira; ++: Revelada frequentemente e de forma indiscutível; +++: Revelada sistematicamente e de forma acentuada.

Como se pode observar, o FG1 foi aquele que expressou menores preocupações com o tema em discussão ainda que reconhecesse a complexidade associada às faturas e que pontualmente referisse aspetos de linguagem e de forma. O FG2 e o FG3 estiveram claramente mais comprometidos com a discussão e mostraram ter mais opiniões de partida sobre a (in) capacidade de as faturas comunicarem informação relevante. Para o FG2 as deficiências das faturas apareceram mais ligadas a questões de linguagem ao passo que para o FG3 foram os aspetos de forma que ganharam maior acuidade. 
No que concerne às quatro ordens de razões do desconhecimento das faturas (Tabelas 3 e 4), emanadas das discussões nas entrevistas, procede-se de seguida à explicação das categorias evidenciadas no âmbito de cada razão.

\section{i) Linguagem}

De entre as questões de linguagem, destaca-se o tecnicismo utilizado para designar algumas componentes dos elementos cobrados. Este aspeto tanto foi reconhecido diretamente por alguns dos consumidores ouvidos como foi detetado a partir de interrogações e comentários que surgiram sobre o significado de diversas rúbricas.

"A questão é a linguagem técnica... e a gente não perceber exatamente a que é que aquilo corresponde...",

"É quase decreto-lei [referindo-se ao tarifário], linguagem muito pouco apelativa e compreensível",

"Tarifa de manutenção!? Deve ser a das reparações que fazem, manutenção da rede geral, antes de chegarem aos ramais...",

"Quota de serviço? Ninguém sabe o que é isso.",

"Calibre do ramal? Sei lá o que é!"

Ainda no que respeita a aspetos de linguagem foi igualmente possível perceber que a falta de clareza advém também da opacidade de diversos elementos da fatura.

"O mais obscuro são as taxas porque as pessoas não percebem o que estão a pagar..."

"Isto é uma leitura normal... não se sabe muito bem o que isto quer dizer, só isso mata qualquer um!"

"É supercomplicado perceber qualquer coisa quando há acertos."

É interessante notar que as dificuldades de interpretação de terminologia usada, ainda que mais notórias entre os consumidores com menos qualificações (FG2), foram transversais a todos os grupos ouvidos. Com seria de esperar, no FG1, dada a formação especializada dos seus elementos, os problemas de linguagem não foram tão pronunciados. Já o FG3 denunciou fortes preocupações com a linguagem sobretudo por considerá-la pouco acessível à generalidade dos consumidores.

\section{ii) Complexidade}

A contribuir para a complexidade das faturas está a forma como estão concebidos os tarifários e a organização do setor. Devido à cobrança conjunta de três serviços - AA, SAR e RSU - há uma multiplicidade de itens na fatura, o que dificulta a sua interpretação. A complexidade que daqui resulta é reconhecida por alguns consumidores que revelaram, por exemplo:

"O problema não está na fatura, está no sistema. Ao tentar ser tão minucioso, o sistema fica muito complexo. Não sei se se ganha muito com isso..."

Uma parte expressiva dos consumidores ouvidos tem consciência de que se pagam conjuntamente com o consumo de água outros serviços.

"É os resíduos, é o saneamento, e sei lá mais o quê... é o ambiente."

Contudo, muitos surpreenderam-se com a presença de certas parcelas, como evidenciado nas seguintes transcrições:

"Também há escalão para as águas residuais? Eles medem as águas residuais?"

"Tem dois saneamentos fixos!" 
Revelou-se também a dificuldade em conhecer a natureza fixa ou variável de alguns itens cobrados.

"A tarifa de manutenção do sistema público de água, eu também não sei o que é. Não é claro se é fixo ou variável, não diz."

"O sistema é muito complexo. É impossível explicá-lo... Fatores todos, uns fixos, outros dependentes do consumo, é absolutamente impossivel perceber alguma coisa daquilo."

Em relação às componentes variáveis dos tarifários, poucos foram os consumidores que sabiam que são praticados IBT e também que há escalões aplicáveis aos outros serviços para além do AA. A maioria dos consumidores auscultados revelou uma ideia algo vaga sobre o assunto:

"Tenho ideia de que se paga mais por $\mathrm{m}^{3}$, se consumirmos mais pagamos mais, mas não faço ideia nenhuma dos escalões, nem coisa nenhuma."

"Como aquilo é por 'escalas'... mesmo que se gaste mais alguma coisa paga-se logo uma taxa superior. X metros é um valor e depois salta."

Só em casos pontuais pareceu existir um conhecimento mais aprofundado da estrutura por blocos dos tarifários:

"Se o valor [a pagar] for mais alto vejo de onde é que veio isto, se cheguei ao 3. ${ }^{\circ}$ escalão......"

"Aqui veem os escalões todos... a pessoa pode começar a jogar com isso. Permite ver onde começa e acaba... eu pelo menos acho que é importante."

A utilização frequente de siglas nas faturas para designar muitas das rúbricas cobradas introduz algumas dúvidas e mesmo uma certa perplexidade em alguns clientes.

"Há para aí umas siglas... havendo espaço mais vale estar lá tudo. Nem toda a gente tem de saber, eu não sei!"

Embora se considere que a complexidade tenha estado presente de forma equiparável nas entrevistas feitas com os FG1 e FG2 ela deriva de aspetos distintos. O FG1 atribui a complexidade das faturas principalmente aos esquemas tarifários. Já o FG2 revelou maior dificuldade em entender a multiplicidade de itens cobrados e a indexação dos valores correspondentes ao pagamento dos SAR e de RSU ao consumo de água.

\section{iii) Forma}

As faturas são por vezes entendidas como documentos pouco cuidados, onde a informação aparece frequentemente desarrumada/desorganizada:

"Aqui as parcelas, ali o total, isto está muito mal arrumado."

Além disso, foi salientada a falta de destaque ao que cada consumidor considera mais importante:

"A única coisa que está em nosso controlo é o consumo variável, devia dizer a parte variável primeiro e depois a parte fixa e depois o total, isso era fundamental para baixar a nossa conta, enfim..."

A utilização de letras de reduzida dimensão emergiu como uma dificuldade adicional para a leitura da fatura, tendo levantando alguma suspeição, em particular entre elementos do FG2, sobre a intenção dos operadores em não dar o devido destaque a determinada informação.

"A letra é muito pequenina."

"Há coisas interessantes e que não se veem logo. Veem com letras mais pequeninas." 
Foram apontadas também diversas falhas no que concerne aos suportes gráficos utilizados nas faturas, como a falta de rigor em termos de títulos, a ausência de legendas para os eixos e/ou a falta de indicação clara quantos às unidades de medida usadas.

"Este 14 não corresponde a este gráfico. Este gráfico não corresponde a este valor. É confuso!"

Por considerarem que são elementos importantes para transmitir informação de forma rápida, foi igualmente criticado pelos consumidores ouvidos o facto de os operadores nem sempre utilizarem gráficos.

"[Referindo-se a uma fatura em concreto] É pena não ter gráficos!"

"Esta [fatura] tem a vantagem do gráfico estar logo no início. Visualmente tem essa mais-valia. Ao passo que nesta temos de virar a página para o ver."

O FG3 revelou-se o mais preocupado com os problemas de forma identificados nas faturas, mostrando ser o grupo com ideias mais definidas sobre este tópico, o se traduziu em diversas recomendações possíveis de melhoria. O FG2 evidenciou a necessidade de dispor de mais apoios gráficos e explicativos das rúbricas presentes na fatura.

\section{iv) Desinteresse}

É de notar que, logo no início das discussões com os consumidores, alguns (principalmente entre os participantes no FG1) desvalorizaram a importância de conhecer melhor as suas faturas. Quando confrontados com a temática a ser tratada (conhecimento/importância das faturas), alguns participantes revelaram algum ceticismo sobre o benefício que poderia resultar de um melhor/mais aprofundado conhecimento das faturas de água.

Os consumidores que se assumiram pouco interessados em conhecer melhor a sua conta de água, ou que revelaram algum desinteresse, mesmo que não assumido, destacaram o fraco peso que os gastos com os serviços de águas têm no conjunto das suas despesas familiares, sobretudo em comparação com outros serviços essenciais, nomeadamente a eletricidade. Para estes, o desinteresse relevado prende-se menos com o documento fatura e mais com os fracos benefícios que consideram poder advir de um maior conhecimento das suas contas de água.

Entre os participantes desinteressados houve também aqueles que sublinharam pouco poder fazer para influenciar os encargos mensais que suportam e que, consequentemente, reconheceram sentir-se pouco incentivados a procurar informação.

"Eu nem sei o que é que lá vem... o problema é esse... eu nem sequer leio... vejo se o valor é estável... eu já nem sei como é que é o documento presentemente."

Esta desmotivação pelo conhecimento das faturas é acentuada pelo reconhecimento de que não há alternativa na escolha do operador e que a água é um bem essencial, sem substitutos. Por este tipo de razões, alguns consumidores consideraram que estão numa posição fragilizada face ao pretenso poder do prestador do serviço.

"Eu acho que não podemos fazer nada. Acho que temos de aceitar e pronto."

Há também uma perceção da fraca relação entre as quantidades consumidas de água e os valores suportados decorrente do peso dos encargos fixos no valor a pagar.

"Quando vejo: consumo $6 \mathrm{~m}^{3}$, ou 4, se consumir menos $10 \%$, pago o quê? Menos 60 cêntimos!? $10 \%$ a mais ou a menos é zero!"

A maioria dos participantes vê as faturas essencialmente como um documento através do qual obtém informação sobre os montantes a pagar mensalmente. A menos que o valor a pagar se desvie substancialmente do "padrão habitual", os consumidores não procuram perceber como se reconstitui esse valor. Alguns participantes revelaram ter um valor de referência e outros atribuíram importância a diferenças expressivas no montante a pagar comparativamente ao mês anterior. 
“Se não houver nada assim extraordinário não consulto."

"Desde que não haja grandes variações em relação ao mês anterior, está tudo bem."

Alguns participantes, pelos seus traços individuais, em especial relacionados com a preocupação de controlar de forma mais ou menos apertada os gastos, dão às faturas mais importância.

“Olhos para elas [faturas de água] sempre que veem, como aliás para qualquer fatura."

Poucos participantes se revelaram preocupados com a utilização moderada do recurso água. No entanto, principalmente entre os consumidores do género feminino e com filhos menores, esta problemática não passou despercebida:

"Fico a pensar... crianças, banhos... Será que estamos a ter um comportamento razoável?"

Adicionalmente parece existir uma clara dificuldade em avaliar através da fatura a razoabilidade dos gastos/consumos.

Para o acompanhamento dos consumos, foi salientado o papel que os gráficos podem ter.

"É importante para que os indivíduos possam ir avaliando a evolução dos seus comportamentos. Quais são os meses do ano e porque razão consomem mais."

Importa assinalar que as dimensões identificadas não são estanques entre si. A existência de deficiências em determinados aspetos tem efeitos múltiplos, criando barreiras à boa comunicação através da fatura. A título de exemplo, a utilização de linguagem pouco acessível, aliada à falta de cuidado com alguns aspetos de forma, potencia atitudes de desinteresse, como evidenciado no excerto seguinte:

"Eu acho que custa a interpretar. Eu começo a ler e atiro para o lado."

\subsection{Reações negativas perante as faturas}

O baixo nível de conhecimento relativamente às faturas e algumas das razões que o explicam põem em causa a eficácia das políticas públicas chave no que respeita à promoção da sustentabilidade do recurso. Efetivamente, a comunicação via fatura não está a funcionar como seria desejável e, consequentemente, a informação que se pretende transmitir, em especial relativamente a preços, chega pouco aos seus destinatários: os consumidores domésticos.

$\mathrm{Na}$ verdade, pelas questões de conteúdo e forma que foram discutidas anteriormente, em alguns casos as faturas parecem dissuasoras de atitudes mais comprometidas por parte dos consumidores. O alheamento revelado por alguns do consumidores vem frequentemente acompanhado de uma elevada desconfiança para com os operadores:

"Já lhe disse, as letras miudinhas... Já lhe disse que é melhor ler-se nas entrelinhas."

Neste contexto, uma parte significativa de consumidores, sobretudo no FG2, entende que os operadores têm como interesse quase exclusivo que os consumidores consumam mais para obterem maiores receitas.

"É para Ihe mexerem mais no bolso."

Por vezes, a falta de clareza parece ser entendida como uma estratégia intencional para limitar o poder reivindicativo dos consumidores:

"A leitura não é assim tão clara porque também não se pretende que as pessoas tenham muita consciência das taxas todas que estão ali e dos encargos todos que pagamos."

A propósito da sensibilização para a escassez do recurso, um dos consumidores disse:

"Os fornecedores querem é que se gaste. A própria televisão tem-se preocupado mais em esclarecer as pessoas. Avisa mais." 
Perante estas ideias, é expectável que qualquer papel que pudesse caber às faturas na comunicação de políticas "não-preço" (por exemplo, através de mensagens de incentivo à poupança de água) esteja a priori comprometido.

Face ao seu conteúdo e função, as faturas naturalmente assumem particular relevância na comunicação das políticas preço. Nesse âmbito, alguns consumidores reconheceram a existência de IBT e, nesse sentido, compreendem que há comportamentos a ajustar:

"O preço é em função do consumo. Quanto mais se consome, mais se paga"

"Esta informação [a respeito dos escalões] permite ver onde começa e acaba... eu pelo menos acho que é importante. (...) A pessoa pode começar a jogar com isso".

No entanto, passa a ideia, por vezes bem alicerçada face ao peso dos encargos fixos, de que os preços associados aos escalões não são verdadeiramente promotores de comportamentos poupadores. Acresce que a mensagem de penalização de consumos elevados através dos preços mais altos torna-se difícil de entender perante a presença na fatura de outros serviços, cuja forma de cobrança (indexada ao consumo de água) não é percebida pela generalidade dos consumidores.

"Aquilo que devia ser mais caro é o que acaba por ser mais barato. Gasta-se mais noutras coisas do que naquilo que é mais essencial. Paga-se menos de água e andamos a pagar contas sei lá de quê."

Independentemente deste retrato algo pessimista da eficácia das faturas na comunicação das políticas, o seu papel não pode ser minimizado. Como um dos participantes afirmou:

"As faturas devem alertar, devem ajudar, informar..."

Foi possível constatar, em vários aspetos analisados, diferenças entre as perspetivas dominantes em cada um dos focus groups. Se é verdade que nalguns casos se confirmaram as expectativas (por exemplo, no que se refere à dificuldade em compreender determinados conteúdos decorrente, de um menor nível de qualificações), outros casos houve em que se verificou que alguns dos problemas enfrentados pelos consumidores são mais transversais do que se esperaria (em especial no que concerne ao desconhecimento sobre algum dos elementos da fatura).

O desconhecimento, bem patente, por exemplo, na forma como são cobradas componentes de águas residuais e resíduos sólidos, tem aparentemente razões distintas. Entre os indivíduos do FG1 o desconhecimento parece estar relacionado com o desinteresse associado a uma desvalorização da importância do conhecimento detalhado das faturas de água. As quantias em causa são pouco expressivas comparativamente a outros encargos familiares, em especial aqueles que são suportados com outros serviços essenciais. Já no FG2, formado por indivíduos com menores qualificações, o desconhecimento é muito motivado pela ideia de que as faturas são complexas e de que pouco podem fazer face ao poder dos operadores. O FG2 foi, de entre os três, o que revelou maior desconfiança em relação aos operadores e aquele que aparentemente mais expectativas tinha em relação ao potencial das faturas enquanto veículo para a promoção de consumos parcimoniosos e com reflexos nos valores suportados. Os indivíduos do FG2 valorizaram especialmente a utilização de linguagem simples (sem tecnicismos) e realçaram a importância das faturas terem tudo "bem explicadinho", associando este aspeto a um princípio de "boa-fé". Por oposição, foram os participantes do FG1 que demonstraram maior preferência por um documento sintético. Os consumidores que formaram o FG3 manifestaram, por comparação com os restantes, uma maior familiaridade com as faturas. Também aqui surgiram preocupações com a utilização de linguagem acessível e de fácil compreensão por todos os grupos da população. Vários participantes revelaram explicitamente que as faturas deviam assegurar o direito à informação, o que exige que a comunicação se faça de forma clara (com recurso a plain language). Neste grupo ficou especialmente patente a preocupação com aspetos gráficos e de forma. 
Por outro lado, as preocupações com a sustentabilidade do recurso estiveram genericamente pouco presentes nos focus groups, o que revela a pouca eficácia das políticas públicas nesta matéria. Ainda assim, foram os indivíduos mais informados e/ou aqueles com filhos em idade escolar os que mais consciência manifestaram, nomeadamente ao referirem a importância de disporem (potencialmente via fatura) de elementos que permitissem avaliar a razoabilidade dos próprios consumos.

Face às deficiências apontadas ao documento fatura, fica assim a ideia de que há melhorias a introduzir na comunicação por esta via, no sentido de aumentar os níveis de conhecimento e/ou de disciplinar os consumos.

\section{Recomendações para a melhoria das faturas}

A importância em comunicar de forma compreensível informação relevante aos consumidores domésticos de água, seja por questões de transparência, seja por se considerar que isso pode ser promotor de comportamentos racionais de consumo, tem sido recentemente reconhecida.

O relatório Skills Outlook 2013 (OECD, 2013) chama a atenção para os baixos níveis de literacia e de numeracia de uma parte significativa da população, mesmo nos países desenvolvidos, sublinhando que, para minorar este problema, os serviços públicos devem comunicar numa linguagem simples.

No âmbito dos serviços de águas, e num contexto internacional, a relatora especial das Nações Unidas para o direito à Água e Saneamento revela também este tipo de preocupações, recomendando que a comunicação de informação aos cidadãos se faça de forma clara e acessível a todos (Albuquerque, 2014).

No contexto português, o regulador económico faz eco destes princípios implementando iniciativas que visam contribuir para a disponibilização de informação "de forma clara e conveniente" aos consumidores de serviços de águas e resíduos, em especial no que respeita aos tarifários aplicáveis aos utilizadores finais, em concordância com o estipulado no Artigo $4 .^{\circ}$ "Dever de informação", da Lei dos Serviços Públicos Essenciais - Lei n. ${ }^{\circ}$ 23/96, de 26 de julho (entretanto alterada pelas Leis n. ${ }^{\circ} 12 / 2008$, de 26 de fevereiro, n. ${ }^{\circ} 24 / 2008$, de 2 de junho, e n. ${ }^{\circ}$ 6/2011, de 10 de março) e no Artigo n. ${ }^{\circ} 61^{\circ}$ "Dever de Informação" do DL n. ${ }^{\circ}$ 194/2009 (Estatutos da ERSAR). Entre as iniciativas do regulador merecem destaque a emissão da Recomendação ERSAR n. ${ }^{\circ 1 / 2010 ~-~ C o n t e u ́ d o ~ d a s ~ F a t u r a s ~ e ~ a ~ p u b l i c a c ̧ a ̃ o ~ d e ~ u m ~ G u i a ~ T e ́ c n i c o ~}$ (Andrade et al., 2012), dirigidas aos prestadores dos serviços e, direcionada para os consumidores, a disponibilização no sítio internet da ERSAR de uma área de Perguntas Frequentes (da qual faz parte um conjunto de "Questões sobre tarifas de serviços de águas e resíduos" e um conjunto de "Questões sobre faturação e leitura de serviços de águas e resíduos") e de "Cadernos de Sensibilização - O Consumidor e os Serviços de Águas e Resíduos" sobre os direitos e deveres dos consumidores.

A literatura científica, ainda que não se debruçando prioritariamente sobre a relevância da comunicação via fatura, apresenta resultados que apoiam a identificação de um conjunto de recomendações (abaixo identificadas pelas letras $A$ a E) e a sua fundamentação. Algumas dessas recomendações encontram igualmente expressão em ideias reveladas pelos consumidores domésticos auscultados:

A) Usar linguagem correta mas simples, evitando o tecnicismo desnecessário ou o emprego de expressões pouco intuitivas

Como tem sido salientado em relatórios internacionais já referidos, os baixos níveis de literacia e numeracia revelados por boa parte da população exigem que as entidades estejam especialmente atentas à linguagem que empregam. Com frequência, encontram-se termos ambíguos, inconsistências na designação de algumas rubricas na mesma fatura e formas pouco 
claras de prestar informações relevantes. Por exemplo, na indicação de parcelas fixas, poderia ser usada a expressão "Tarifa fixa do serviço X" e explicitado o seu valor (relativo ao período de cobrança da fatura), evitando nomeadamente a apresentação de "valor unitário vezes Y".

Internacionalmente é possível identificar algumas boas práticas para a utilização de linguagem acessível a todos. A título de exemplo refira-se o desenvolvimento no Reino Unido de um guia, disponível online ${ }^{2}$, aplicável a todos os sítios governamentais na internet, sobre como criar e editar documentos e organizar páginas.

\section{B) Dar mais destaque às quantidades consumidas}

Uma vez que o elemento sobre o qual os consumidores têm algum controlo é a quantidade consumida, esta merece ser devidamente destacada.

As quantidades são indicadas na fatura mas com menor visibilidade do que os valores a pagar, não apelando para que os consumidores olhem com atenção para o volume de água usada. Os operadores geralmente apresentam históricos de consumo, normalmente sob a forma de gráficos (claramente valorizados pelos consumidores), que nem sempre são informativos e/ou rigorosos.

Assim, na comunicação das quantidades poderiam ser exploradas as potencialidades de gráficos bem identificados (devidamente acompanhado de títulos adequados, eixos claramente identificados, apresentação de unidades de medida) e visualmente atrativos.

C) Providenciar elementos de comparação que permitam ao consumidor aferir a razoabilidade do seu consumo

Permitir que cada família possa saber se está a consumir em excesso é fundamental para promover a adaptação dos padrões de consumo. Apesar da fraca elasticidade preço da procura dos serviços de águas, existe já alguma literatura recente que corrobora a ideia de que as famílias reagem perante informação sobre os consumos de outras com quem se comparam. Ferraro e Price (2013) analisaram o impacto da disponibilização de informação relativa a níveis médios de consumo de famílias vizinhas (social comparison), num estudo sobre o consumo residencial em Atlanta, Georgia. Os resultados revelaram que a utilização de referentes baseados na comparação social de consumos exerce um efeito expressivo sobre o comportamento de procura de água. Esse efeito revelou-se maior do que o decorrente da utilização de mensagens poupadoras ou de informação técnica apenas. Os autores concluíram ainda que as comparações sociais são mais eficazes entre as famílias identificadas como tendo uma elasticidade preço da procura menor: os maiores consumidores. Porém, dado que os efeitos vão diminuindo ao longo do tempo, os autores concluem que existem complementaridades importantes entre estratégias preço e "não-preço".

Em Portugal, e nesta matéria, os operadores limitam-se neste momento a disponibilizar, quando muito, informação sobre os consumos passados da família (por vezes são apresentadas médias de consumo de acordo com o historial do cliente), não fornecendo dados que permitam avaliar o consumo do agregado familiar face a outros comparáveis.

A fatura poderia passar a incluir um referente, tal como: "em média uma família com $\mathrm{N}$ elementos neste concelho consome mensalmente $\mathrm{Z} \mathrm{m}^{3}$ ".

D) Tornar mais visível o impacto sobre os encargos suportados (valor a pagar) de uma redução no consumo

Existe a perceção de que a redução do consumo se repercute muito pouco no valor a pagar. Tal como Worthington e Hoffman (2008) ou Bolland e Wittington (2000) realçam, a cobrança de tarifas fixas elevadas contribui para a fraca interpretação do preço marginal da água.

2 Disponível em https://www.gov.uk/government-digital-guidance/content-publishing e consultado em abril de 2015. 
Contudo, a indexação dos encargos variáveis de SAR e de RSU à quantidade consumida no caso português (desconhecida por uma boa parte dos consumidores) aumenta o efeito de variações no consumo sobre o total a pagar. A ERSAR veio recentemente enfatizar a obrigatoriedade das faturas passarem a explicitar esta indexação.

Para realçar o impacto de consumos parcimoniosos sobre os encargos suportados sugere-se que na fatura conste uma mensagem do tipo: "Se a sua família consome entre 6 e $15 \mathrm{~m}^{3}$, a poupança de $1 \mathrm{~m}^{3}$ permitirá gastar menos $X €$ em AA, Y€ em SAR e W€ em RSU. Em conjunto, pagará menos Z€”.

E) Não usar o mesmo modelo de fatura para diferentes tipologias de consumidores (e.g. domésticos e não domésticos)

A disponibilização de informação não aplicável aos consumidores domésticos, por exemplo valores de encargos fixos de AA para contadores de tubuladura superior à aplicada, pode introduzir confusão. Tipicamente, os operadores abusam do recurso a uma fatura muito despersonalizada. A utilização de um único modelo para todos os consumidores pode ser contraproducente.

\section{Conclusão}

Uma clara compreensão das políticas é geralmente condição para que produzam os efeitos desejados. No caso das águas, as políticas que visam a sustentabilidade do recurso apelam frequentemente para alterações nos comportamentos dos consumidores que só podem ser conseguidas se estes agentes económicos entenderem os sinais emanados pelos preços e a razoabilidade das mensagens associadas às políticas "não-preço".

Ao mesmo tempo que instâncias internacionais chamam a atenção para a necessidade dos governos e dos prestadores dos serviços comunicarem de forma simples e clara para que a informação chegue a todos, trabalhos de investigação recentes têm vindo a chamar a atenção para o baixo conhecimento revelado pelos clientes domésticos relativamente às suas próprias contas e às condições de funcionamento dos serviços de águas. A literatura existente sobre o papel das faturas (canal de comunicação universal e regular) é, em todo o caso, escassa e geralmente não capta a perspetiva dos utilizadores dos serviços, contrastando com a atualidade das preocupações recentes de reguladores e outras instâncias internacionais.

O presente trabalho pretendeu estudar as razões do desconhecimento dos consumidores relativamente às suas faturas a partir de uma abordagem qualitativa com recurso à utilização de focus groups. A partir dessas razões procurou-se extrair um conjunto de recomendações para a melhoria da comunicação de informação relevante, via fatura, aos clientes.

A informação recolhida revelou-se rica e esclarecedora, permitindo encontrar quatro grandes ordens de motivos para o desconhecimento: linguagem, complexidade, forma e desinteresse. Não estando em discussão a questão da simplificação das estruturas tarifárias (que no formato atual recomendado pelo regulador muito contribuem para a complexidade das faturas), ficou bem claro que o documento fatura pode ser melhorado tanto no conteúdo como na forma. Essas melhorias podem tornar o documento mais claro, mais apelativo e mais interessante. $\mathrm{O}$ uso de linguagem correta mas simples, bem como o fornecimento de informação que permita aos consumidores avaliarem a razoabilidade dos seus consumos e perceberem melhor o impacto sobre o encargo de uma maior poupança de água são alguns dos princípios destacados.

Revelando a atualidade da temática, o artigo $67 .{ }^{\circ}$ do Decreto-Lei n. ${ }^{\circ}$ 194/2009, de 20 de agosto, na redação que Ihe foi dada pela Lei da Fatura Detalhada, veio impor um conjunto de obrigações às entidades gestoras que prestam serviços de águas e resíduos a utilizadores finais quanto à informação a constar nas respetivas faturas. O Plano de Reestruturação do Setor das Águas 
refere igualmente, e de forma explícita, a importância da fatura como veículo de prestação de informação transparente aos cidadãos. Contudo, se a Lei da Fatura Detalhada vem ao encontro de algumas das preocupações reveladas (nomeadamente quanto à inconsistência ou falta de rigor, exigindo uma informação mais completa e padronizada), não responde cabalmente às exigências de explicitação da relação entre quantidades consumidas e encargos suportados e deixa ainda de fora aspetos importantes relacionados com a inclusão de referentes de comparação e com alguns aspetos de forma. Sem a consciencialização dos cidadãos relativamente à importância das faturas e sem um trabalho sério para as tornar mais claras e atrativas, os efeitos práticos sobre o conhecimento dos consumidores serão provavelmente reduzidos. Obviamente que a complementaridade da fatura com outros canais de comunicação para a transmissão de informação adicional ou mais detalhada, nomeadamente os sítios web dos operadores e do regulador, não deve também ser ignorada.

Ultrapassar alguns dos problemas apontados pelos clientes contribuirá para evitar reações negativas que são bastante correntes, como a desconfiança e a desresponsabilização, e que minam a eficácia das políticas públicas que se pretendam desenhar para o setor.

\section{Referências bibliográficas}

Arbués, F.; Garcia-Valinas, M.A.; Martinez-Espineira, R. (2003) Estimation of residential Water demand: A state-of-the-art review, Journal of Socio-Economics, 32(1), 81-102.

Albuquerque, C. de (2014) Realising the human rights to water and sanitation: A handbook by the UN special rapporteur Catarina de Albuquerque, UN-OHCHR, Lisboa.

Andrade, I.; Mesquita, A.; Santos, C. (2012) Relação das entidades gestoras com os utilizadores dos serviços de águas e resíduos, Guia Técnico n. ${ }^{\circ} 20$ / Technical Guide No. 20, ERSAR, Lisboa, Portugal.

Binet, M-E.; Carlevaro, F.; Paul, M. (2013) Estimation of Residential Water Demand with Imperfect Price Perception, Environmental Resource Economics, 59, 561-581.

Boland, J.J.; Whittington, D. (2000) The political economy of water tariff design in developing countries: Increasing block tariffs versus uniform price with rebate, in Dinar, Ariel (ed.) The Political Economy of Water Pricing Reforms, Oxford University Press, 215-235.

Bryman, A.; Bell, E. (2007) Business research methods, Oxford University Press, 2nd edition, New York.

Correia, R.; Roseta-Palma, C. (2014) Behavioural Economics in Water Management: An overview of behavioural economics applications to residential water demand, in Ulph, Alistair; Southerton, Dale (eds.) Sustainable Consumption: Multi-disciplinary Perspectives In Honour of Professor Sir Partha Dasgupta, Oxford Scholarship Online, 196-223.

ERSAR (2010) Recomendação ERSAR n. ${ }^{1 / 2010}$, Conteúdos das faturas dos serviços públicos de abastecimento de água para consumo humano, de saneamento de águas residuais urbanas e de gestão de resíduos urbanos prestados aos utilizadores finais ("Conteúdos das faturas"), Entidade Reguladora de Serviços de Águas e Resíduos, Lisboa.

ERSAR (2013) Relatório Anual do Sector de Águas e Resíduos em Portugal (2012), Volume 1 Caraterização geral do setor, Entidade Reguladora de Serviços de Águas e Resíduos, Lisboa.

ERSAR (2014) Relatório Anual do Sector de Águas e Resíduos em Portugal (2013), Volume 1 Caraterização geral do setor, Entidade Reguladora de Serviços de Águas e Resíduos, Lisboa.

Ferraro, P.; Price, M. (2013) Using Nonpecuniary Strategies to Influence Behavior: Evidence from a Large-Scale Field Experiment, Review of Economics and Statistics, 95(1), 64-73.

Gaudin, S. (2006) Effect of price information on residential water demand, Applied Economics, 38(4), 383-393. 
Martins, R.; Cruz, L.; Barata, E.; Quintal, C. (2013) Assessing social concerns in water tariffs, Water Policy, 15(2), 193-211.

Martins, R.; Moura e Sá, P. (2011) Promoting sustainable residential water use: A Portuguese case study in ownership and regulation, Policy Studies, 32(3), 291-301.

Monteiro, H.; Roseta Palma, C.; Martins, R. (2014) How much do you pay for water?, IWA (International Water Association) World Water Congress \& Exhibition - 2014 - "Shaping our water future", Lisbon 22-26 September.

Morgan, D. (1998) Planning Focus Groups - Focus Group Kit 2, Sage Publication, Thousand Oaks, California.

Nataraj, S.; Hanemann, M. (2011) Does Marginal Price Matter? A Regression Discontinuity Approach to Estimating Water Demand, Journal of Environmental Economics and Management, 61, 198-212.

Nieswiadomy, M.; Molina, D. (1989) Comparing Residential Water Demand Estimates under Decreasing and Increasing Block Rates using Household Data, Land Economics, 65(3), August, 291-289.

OECD (2010) Pricing Water Resources and Water and Sanitation Services, OECD Studies on Water, OECD Publishing.

OECD (2013) OECD Skills Outlook 2013: First Results from the Survey of Adult Skills, OECD Publishing.

Van den Bergh, J. (2008) Environmental regulation of households: An empirical review of economic and psychological factors, Ecological Economics, 66, 559-574.

Worthington, A.; Hoffman, M. (2008) An empirical survey of residential water demand modelling, Journal of Economic Surveys, 22(5), 842-871. 